\title{
Swelling Measurements of a Low Rank Coal in Supercritical $\mathrm{CO}_{2}$
}

\author{
Ferian Anggara $^{1,2}$, Kyuro Sasaki ${ }^{1}$, Yuichi Sugai ${ }^{1}$ \\ ${ }^{1}$ Department of Earth Resources Engineering, Kyushu University, Fukuoka, Japan \\ ${ }^{2}$ Department of Geological Engineering, Gadjah Mada University, Yogyakarta, Indonesia \\ Email: ferian@ugm.ac.id, krsasaki@mine.kyushu-u.ac.id, sugai@mine.kyushu-u.ac.id \\ Received March 28, 2013; revised April 30, 2013; accepted May 27, 2013
}

Copyright (C) 2013 Ferian Anggara et al. This is an open access article distributed under the Creative Commons Attribution License, which permits unrestricted use, distribution, and reproduction in any medium, provided the original work is properly cited.

\begin{abstract}
Coal swelling in the presence of water as well as $\mathrm{CO}_{2}$ is a well-known phenomenon, and these may affect the permeability of coal. Quantifying swelling effects is becoming an important issue to verify the suitability of particular coal seams for $\mathrm{CO}_{2}$-enhanced coal bed methane recovery projects. In this report, coal swelling experiments using a visualization method in the $\mathrm{CO}_{2}$ supercritical conditions were conducted on crushed coal samples. The measurement apparatus was designed specifically for the present swelling experiment using a visualization method. Crushed coal samples were used instead of block coal samples to shorten equilibrium time and to solve the problem of limited availability of core coal samples. Dry and wet coal samples were used in the experiments because there is relatively limited information about how the swelling of coal by $\mathrm{CO}_{2}$ is affected by water saturation. Moreover, some coal seams are saturated with water in initial reservoir conditions. The maximum volumetric swelling was around $3 \%$ at $10 \mathrm{MPa}$ for dry samples and almost half that at the same pressure for wet samples. The wet samples showed lower volumetric swelling than dry ones because the wet coal samples were already swollen by water. Experimental results obtained for swelling were comparable with other reports. Our visualization method using crushed samples has advantages in terms of sample preparation and experimental execution compared with the other methods used to measure coal swelling using block samples.
\end{abstract}

Keywords: Coal Swelling Experiments; Visualization Method; $\mathrm{CO}_{2}$-Enhanced Coal Bed Methane Recovery; Low Rank Coal

\section{Introduction}

$\mathrm{CO}_{2}$ capture and storage (CCS) is a method expected to reduce emission of $\mathrm{CO}_{2}$ into the atmosphere. In fact, geological sequestration is most likely to be the only option that will allow $\mathrm{CO}_{2}$ storage in large enough quantities over long geological periods of time. One of the geological sequestration options is injection of $\mathrm{CO}_{2}$ into coal seams. This option is considered to be a safe and effective method for permanently storing $\mathrm{CO}_{2}$ with the added value of enhanced coal bed methane recovery $\left(\mathrm{CO}_{2}\right.$-ECBMR). It has been suggested that the $\mathrm{CO}_{2}$ sorption capacity of coal seams is typically between 2 to 10 times higher than that for $\mathrm{CH}_{4}$ depending on coal rank [1-3].

$\mathrm{CO}_{2}$ injection into a coal seam increases the rate of $\mathrm{CH}_{4}$ production considerably [4]. However, $\mathrm{CO}_{2}$ is also known as a swelling agent for coal. Coal swelling in the presence of water or $\mathrm{CO}_{2}$ is a well-known phenomenon, and may affect the permeability of coal. Because the permeability of a coal is perhaps the most important factor controlling the economic viability of $\mathrm{CO}_{2}$-ECBMR, thus quantifying the effect of swelling on permeability has become an important issue.

A number of studies investigating $\mathrm{CO}_{2}$-induced swelling have been published. The maximum volumetric swelling has been reported as $1 \%-5 \%$ depending on coal rank [5-7]. Reduction of $\mathrm{CO}_{2}$ injectivity has been observed in some $\mathrm{CO}_{2}$-ECBMR field trials. One of these projects was carried at Yubari, Hokkaido, Japan. The Yubari pilot project for $\mathrm{CO}_{2}$-ECBMR identified the problem of low injectivity of $\mathrm{CO}_{2}$ caused by a reduction in permeability induced by coal swelling [3]. The decay ratios of daily $\mathrm{CO}_{2}$ injection rate measured in the Yubari pilot test are shown in Figure 1.

A field experiment of $\mathrm{CO}_{2}$-ECBMR carried out in the upper Silesian basin of Poland is another example of a pilot project that observed decreasing injectivity caused by swelling. Evaluation of wellhead pressure and temperature data during the pressure buildup and fall-off of 
the intermittent injection periods, considering phase behavior and density changes of the $\mathrm{CO}_{2}$, showed that the buildup time decreases, and the fall-off time increases over time. In addition, the steep decrease at the beginning of the curve during start-up (with water down the hole) disappeared in November and December 2004. Both observations indicate that permeability reduced over time [8]. The reduced injectivity was presumably a result of swelling of the coal after contact with $\mathrm{CO}_{2}$.

The only successful $\mathrm{CO}_{2}$-ECBMR project so far was run between 1995 and 2001 at the Allison Unit in the San Juan Basin in New Mexico, USA, but no monitoring project was associated with this pilot [10]. It has been recognized from the pilot test results that reduction of permeability induced by coal swelling is one of the main technical issues that needs to be resolved to put economical, large-scale $\mathrm{CO}_{2}$-ECBMR into practice worldwide.

In the case of $\mathrm{CO}_{2}$-ECBMR, adsorption of $\mathrm{CO}_{2}$ gas, which has greater sorption capacity than $\mathrm{CH}_{4}$, would cause coal matrix swelling and thus, in contrast to $\mathrm{CH}_{4}$ desorption, potentially reduce the cleat permeability of a coal seam. Therefore, it is important to quantify the swelling of coal induced by $\mathrm{CO}_{2}$ adsorption.

Most swelling experiments have been conducted using core/block coal samples $[6,7,11-13]$, so the equilibrium time was long depending on core block size. Indonesia has many coal resources as well as coal bed methane, so shows potential for $\mathrm{CO}_{2}$-ECBMR sites. However, there is a lack of research of coal behavior after introducing $\mathrm{CO}_{2}$; in particular, coal swelling caused by $\mathrm{CO}_{2}$ adsorption. Thus, our objective was to investigate the swelling characteristics of Indonesia low rank coal (LRC) up to 10 $\mathrm{MPa}$. Crushed coal samples that were treated as block samples have been used in the experiments to allow faster equilibrium time and to solve the problem of limited availability of core samples from deep underground.

\section{Samples and Methods}

\subsection{Samples}

Coal core samples taken from coal seams deep under-

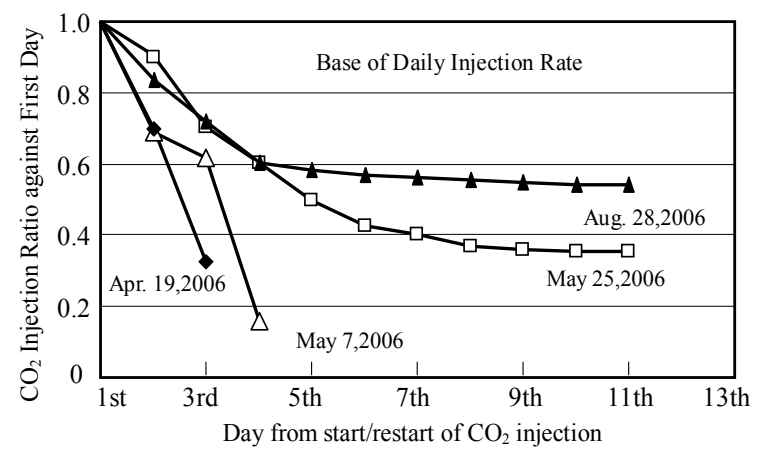

Figure 1. Decay ratio of daily $\mathrm{CO}_{2}$ injection rate monitored at Yubari ECBM-pilot test [9]. ground are very limited. It's costly and technically difficult to obtain representative core samples from deep underground. Furthermore, coal that is anisotropic causes other difficulties with regard to analysis and reproducibility. Therefore, to overcome these difficulties, crushed coal samples were used instead of core samples.

Three coal samples of Indonesia LRC were used in the swelling experiments. Their properties are summarized in Table 1.

\subsection{Apparatus}

A visualization method was used to observe the coal swelling evaluated by surface movement of a column of coal particles. Figure 2 shows a schematic diagram of the measurement apparatus. The measurement apparatus was designed specifically for this experiment, and consisted of a high-pressure cell with two glass windows, a hot water bath with a circulation pump, an electric pressure gauge with a precision of $0.01 \mathrm{MPa}$ (GE Druck Ltd, DPI 282), thermocouples, an illumination source and line valves. The cell temperature was kept at $48^{\circ} \mathrm{C}$ by circulation of hot water through a circular jacket covering the cell, and the apparatus was positioned in a thermally insulated box.

A digital camera was used to take photographs continuously during the experiment. All measurement data from the camera, pressure transducer and thermocouple were logged into the data acquisition system continuously.

\subsection{Procedures}

The procedure for coal swelling experiments was as follows:

Step 1. Sample preparation

Measurements were performed in a glass cylinder 7.35 $\mathrm{mm}$ in diameter and $50 \mathrm{~mm}$ in length with a high precision scale. Two cylinders were placed in the pressure cell

Table 1. Detail coal properties for $\mathrm{CO} 2$ swelling experiments.

\begin{tabular}{cccc}
\hline Adb & SK-01 & SK-02 & SK-03 \\
\hline Moisture, \% wt & 10.68 & 11.63 & 7.53 \\
Ash, \% wt & 4.19 & 2.44 & 10.31 \\
Volatile matter, \% wt & 40.34 & 41.72 & 45.17 \\
C, \% wt & 55.18 & 57.09 & 53.76 \\
H, \% wt & 4.22 & 4.49 & 4.62 \\
N, \% wt & 0.72 & 0.79 & 0.73 \\
Sulfur, \% wt & 0.12 & 0.19 & 0.25 \\
$\mathrm{R}_{0}, \%$ & 0.47 & 0.47 & 0.45 \\
\hline
\end{tabular}




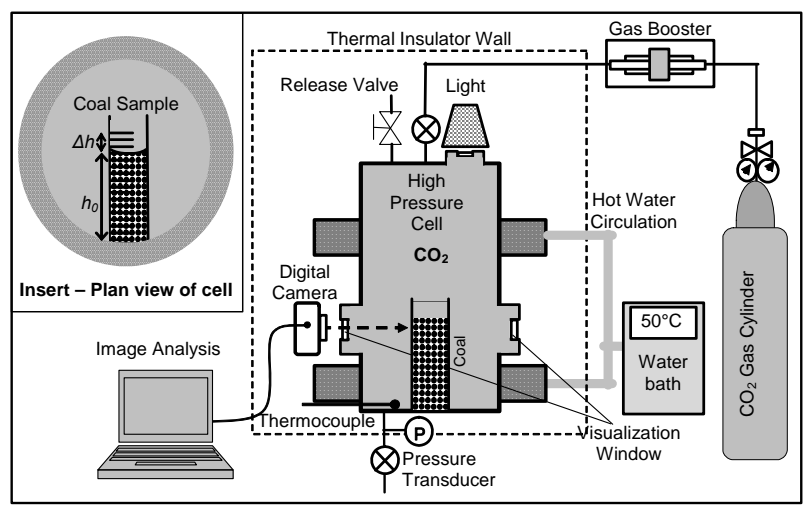

Figure 2. Schematic diagram of coal swelling measurement system using visualization method.

for each measurement. Each cylinder was filled with dry or water-saturated crushed coal particles.

The crushed coal samples were sieved into grain sizes of $200-250 \mu \mathrm{m}$. For dry samples, crushed coal was put into an incubator at $60^{\circ} \mathrm{C}$ for $48 \mathrm{~h}$ under vacuum. After complete drying, approximately $1 \mathrm{~g}$ of sample was placed into a glass cylinder and centrifuged at $3000 \mathrm{rpm}$ for $10 \mathrm{~min}$. These conditions were equivalent to a relative centrifugal force (RCF) of 554.4 as defined by Equations (1) and (2). The results shown in Figure 3 confirm that there was no difference in the coal column after $3000 \mathrm{rpm}$.

$$
\begin{gathered}
R C F=\frac{r \omega^{2}}{g}, \\
R C F=1.12 \times 10^{-5} r_{c m} N_{R P M}^{2},
\end{gathered}
$$

where $g$ is the gravitational acceleration of earth, $r$ is the rotational radius, $\omega$ is the angular velocity in radians per unit time, $r_{c m}$ is the rotational radius measured in centimeters $(\mathrm{cm})$ and $N_{R P M}$ is rotational speed measured in rpm.

For saturated samples, approximately $1 \mathrm{~g}$ of crushed sample and $1 \mathrm{~mL}$ of pure water were filled in the cylinder and then it was centrifuged at $3000 \mathrm{rpm}$ for $10 \mathrm{~min}$ to introduce air and ensure close packing of the sample. Centrifugation was used to allow accurate measurement of initial column height and ensure that the sample was fully saturated with water. Both samples were placed in the pressure cell for $24 \mathrm{~h}$ before $\mathrm{CO}_{2}$ injection.

Step 2. Swelling Measurement

The cell temperature was set at $48^{\circ} \mathrm{C}$ and the $\mathrm{CO}_{2}$ injection pressure was increased in a series of stepwise up to $10 \mathrm{MPa}$. The system was maintained at each pressure step at least for $48 \mathrm{~h}$ and even more. The equilibrium time required for swelling of coal induced by $\mathrm{CO}_{2}$ adsorption depends on the size of the sample. A bigger coal sample will take longer to reach equilibrium and vice versa. In our experiments, most of the swelling occurred

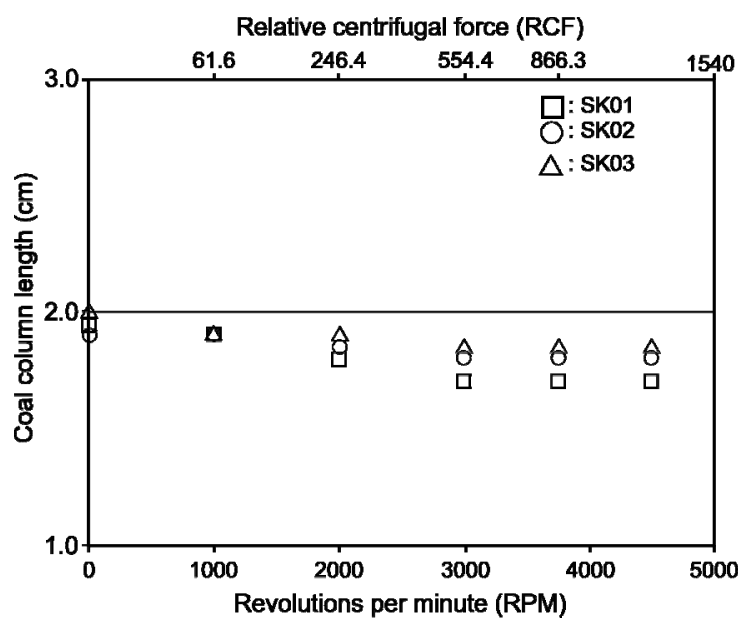

Figure 3. Column length of change as a function of relative centrifugal force in $\mathbf{1 0}$ minutes.

within $24 \mathrm{~h}$ for each pressure step. After measurement at the maximum step, the pressure was decreased to atmospheric conditions to allow comparison of final and initial heights of the coal column.

The upward movement of the column surface was measured against pressure and termed change of column length $(\alpha)$. The proportion length of change, $\alpha(\%)$, and volumetric swelling, $\beta(\%)$, are defined by Equations (3) and (4).

$$
\begin{gathered}
\alpha=\frac{\Delta h}{h_{0}\left[1-K\left(p-p_{0}\right)\right]} \times 100 \% \\
\beta=\frac{\left(\pi r^{2} \Delta h\right)}{V_{0}\left[1-K\left(p-p_{0}\right)\right]} \times 100 \%
\end{gathered}
$$

where $\Delta h$ is increase length caused by $\mathrm{CO}_{2}$-induced swelling, $K$ is compressibility factor $\left(\mathrm{MPa}^{-1}\right), V_{0}$ is initial volume $\left(\mathrm{cm}^{3}\right), r$ is radius of cylinder $(\mathrm{cm}), p$ is pressure $(\mathrm{MPa})$ and $p_{0}$ is initial pressure (MPa).

\section{Results and Discussion}

\subsection{Swelling Experiments}

Crushed samples with particle sizes of $200-250 \mu \mathrm{m}$ were used to avoid particle-packing problems. The samples were centrifuged to ensure that the particles packed into interstitial spaces and were distributed evenly. In addition, Busch et al. [14] reported that sorption rate did not change significantly with increasing grain size $>100$ $\mu \mathrm{m}$, thereby increasing ash content during grinding can be eliminated.

Swelling was represented by upward surface movement of the coal packing column, as shown in Figure 4. As shown in Equation (5), the total initial volume $\left(\bar{V}_{0}\right)$ is equal to the volume of each particle $\left(v_{i}\right)$ and $\mathrm{CO}_{2}$ gas filling the interstitial space. Because swelling of coal 


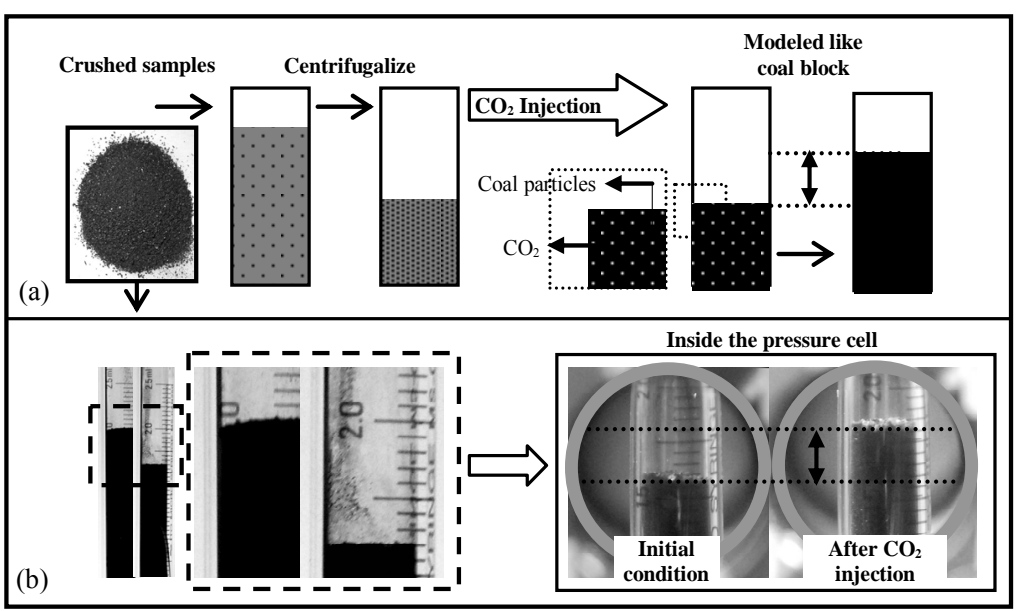

Figure 4. (a) Model showed the experimental procedure for crushed samples which was modeled like coal block; (b) Picture taken during experiment showed different column height after put in the centrifuge (left) and inside the pressure cell before and after $\mathrm{CO}_{2}$ injection (right).

samples is proportional to adsorbed $\mathrm{CO}_{2}$ gas molecules and $\mathrm{CO}_{2}$ mass was kept constant at each pressure step, it was considered that the total initial volume was equivalent to the total volume of each particle. Moreover, the swelling ratio was the ratio of the total volume of the particles at a certain pressure $\left(P_{n}\right)$ to the initial volume of the particles, as given in Equation (6).

$$
\begin{gathered}
\bar{V}_{0}=\sum_{i=1}^{n} v_{i 0}+\bar{V}_{C O_{2}}, \\
\beta=\frac{\sum_{i=1}^{n} v_{i} P_{n}}{\sum_{i=1}^{n} v_{i 0}}=\frac{\bar{V}_{P_{n}}}{\bar{V}_{0}} .
\end{gathered}
$$

Because upward surface movement of the coal column was assumed to be the total expanded volume for each particle, consequently, crushed samples were modeled like coal block. A diagram illustrating this model is shown in Figure 4.

Most of the swelling in the samples occurred within 24 $\mathrm{h}$ of exposure to $\mathrm{CO}_{2}$; after that, swelling increased slightly over a considerable length of time, as depicted in Figure 5. The length of both dry and wet sample columns increased with increasing $\mathrm{CO}_{2}$ pressure. A rapid increase in length was observed in the low pressure range ( $\leq 6 \mathrm{MPa})$, and the maximum length was reached between 8 and $10 \mathrm{MPa}$.

The results of volumetric swelling for three coal samples as a function of pressure and gas density are plotted in Figure 6. Previous studies observed that $\mathrm{CO}_{2}$-induced coal swelling fitted the Langmuir model $[11,13]$. The Langmuir model has been widely used and is used as a standard by many industries. However, it gave a poor fit in the pressure range above $6 \mathrm{MPa}$ [6]. As an alternative, Day et al. [6] suggested that the Dubinin-Radushkevich
(D-R) adsorption model can give a better fit. The D-R model uses gas density instead of pressure according to Equation (7) [7]:

$$
\varepsilon=\varepsilon_{\max } \mathrm{e}^{-D\left[\ln \left(\rho_{a} / \rho_{g}\right)\right]^{2}},
$$

where $\varepsilon_{\max }$ is the maximum volumetric swelling of the coal, $\rho_{g}$ is the density of the gas at the temperature and pressure, $\rho_{a}$ is the density of the condensed phase on the coal surface, and $D$ is a constant that is related to the enthalpy of adsorption. $\rho_{a}$ for $\mathrm{CO}_{2}$ is $1028 \mathrm{~kg} \mathrm{~m}^{-3}$ and both $D$ and $\varepsilon_{\max }$ are considered empirical curve-fitting parameters. The gas density $\left(\rho_{g}\right)$ at each pressure step was calculated using the PROPHAT program. Figure 6 shows a plot of the D-R model. A summary of the results for both the D-R and Langmuir models is presented in Table 2.

Based on these results, the maximum volumetric swelling ratio measured is very similar to ones reported by [5,6,15-17], who used blocks and crushed coal samples. The maximum swelling from [6] with Ro $0.89 \%$ was $\sim 2.6 \%$ at around $8 \mathrm{MPa}$ and $40^{\circ} \mathrm{C}$. Moreover, the maximum swelling of lignite samples reported by [5] was around $4.18 \%$ at $1.5 \mathrm{MPa}$.

Day et al. [6] used block coal with dimensions of $30 \times$ $10 \times 10 \mathrm{~mm}$, while [5] used pencil-shaped samples that were $10 \mathrm{~mm}$ in length and $4 \mathrm{~mm}$ in diameter. Such samples are difficult to prepare because LRC tends to break when cut into small pieces using a rock cutter with water as a lubricant. Therefore, swelling experiments using crushed coal are advantageous in terms of sample preparation and experimental apparatus compared with ones using blocks.

$\mathrm{CO}_{2}$ adsorption equilibrium is reached faster for coal of smaller grain size [18]. For the crushed samples used in this study, swelling equilibrium time, which correlates 


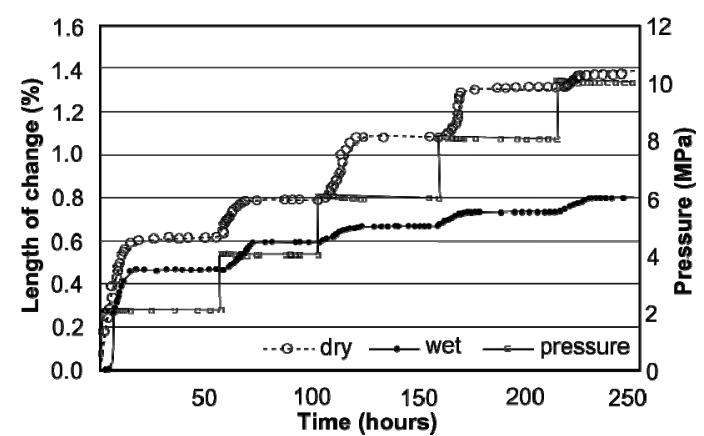

Figure 5. Length of change as a function of time and pressure.

Table 2. D-R and Langmuir's parameters for three coal samples.

\begin{tabular}{ccccccc}
\hline & \multicolumn{2}{c}{ SK-01 } & \multicolumn{2}{c}{ SK-02 } & \multicolumn{2}{c}{ SK-03 } \\
\cline { 2 - 7 } & Dry & Wet & Dry & Wet & Dry & Wet \\
\hline \multicolumn{7}{c}{$D$-R's Model } \\
$\varepsilon_{\max }(\%)$ & 2.81 & 1.45 & 3.33 & 1.57 & 3.04 & 1.51 \\
$\mathrm{D}$ & 0.0859 & 0.0827 & 0.0761 & 0.0910 & 0.0827 & 0.0953 \\
& \multicolumn{7}{c}{ Langmuir's Model } \\
$\varepsilon_{L}(\%)$ & 3.53 & 1.96 & 4.53 & 2.34 & 3.95 & 2.17 \\
$\mathrm{P}_{\mathrm{L}}(\mathrm{MPa})$ & 4.53 & 5.07 & 4.82 & 6.58 & 4.63 & 6.46 \\
\hline
\end{tabular}

strongly with adsorption equilibrium time, was shorter than that for blocks. Reucroft and Sethuraman [5] employed an exposure time of $200 \mathrm{~h}$ in their study. In our experiments, maximum swelling occurred within $12-24$ $\mathrm{h}$ for each pressure step. This was another benefit of using crushed samples.

One of the remaining concerns of using crushed samples was whether the samples return to their original position or not. Coal swelling experiments using block samples showed that all of the coal samples return to their original dimensions after removal from $\mathrm{CO}_{2}[6,7]$. In the present study using crushed coal, we observed the same tendency. Unlike some liquid solvents, exposure to gas does not impart enough molecular mobility to allow relaxation of the structure of coal. Thus, the coal remains elastic, and the swelling process is reversible [19].

Otake and Suuberg [17] reported that the packing density of particles could affect swelling measurements and introduce significant artifacts. To solve this problem, we used small particle sizes $(200-250 \mu \mathrm{m})$ and sample columns were centrifuged to ensure that the particles packed into the interstitial spaces and were distributed evenly. Our results suggest that the processes of swelling are similar in crushed and block coal samples.

The experimental results shown in Figure 6 indicate that volumetric expansion of wet coal is lower than that of dry samples. Swelling of wet coal decreased by
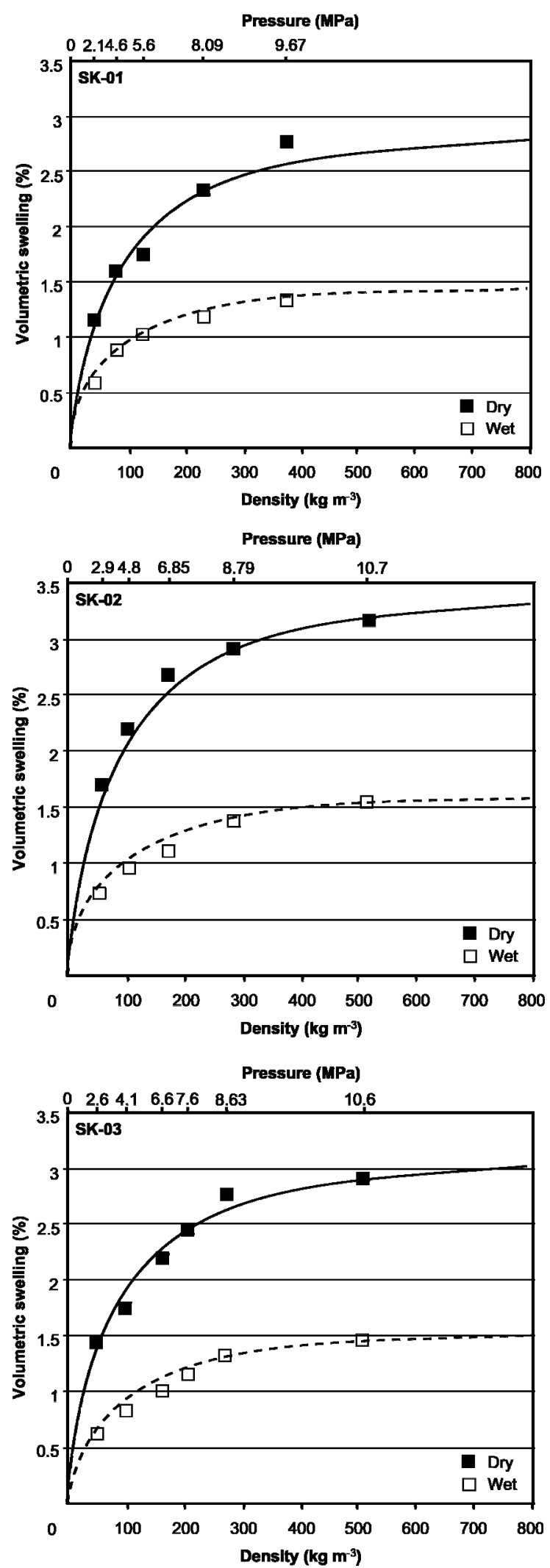

Figure 6. Volumetric expansion of the three coal samples at $48^{\circ}$ under exposure to $\mathrm{CO}_{2}$, the line plot represents the modified $D-R$ model results. 
around $50 \%$ compared with that of dry coal. In accordance with [7], the effect of moisture on the amount of swelling is higher in LRC samples.

When considering the wet samples, one should remember that they are actually already swollen because of the presence of moisture. It has been suggested that the mechanism of swelling is the same in both water and gas [20]. Therefore, the total volumetric swelling of wet coal is the sum of swelling induced by both water and gas.

Considering the crushed coal samples used in this study, instead of swelling both perpendicular and parallel to the bedding plane, experimental results only showed "iso-swelling". The term iso-swelling was used to show that volumetric swelling was calculated without considering the difference between linear swelling parallel and perpendicular to the bedding plane.

In fact, based on some previous studies, linear swelling is significantly different between perpendicular to bedding plane and parallel to the bedding plane. Swelling varies by $30 \%$ - $400 \%$ depending on the coal properties, and perpendicular swelling is always greater than parallel $[6,11,12,21]$.

To investigate this phenomenon, some equations have been used to predict linear swelling parallel and perpendicular to the bedding plane. In swelling experiments using a strain gauge where volumetric swelling was calculated as twice the strain parallel to the bedding plus the strain perpendicular to the bedding $[11,12]$, the following equation was used:

$$
\frac{\Delta V}{V}=\varepsilon_{v s}=\varepsilon_{l s 1}+\varepsilon_{l s 2}+\varepsilon_{l s 3},
$$

where $\varepsilon_{v s}$ is volumetric swelling, and $\varepsilon_{l s 1}, \varepsilon_{l s 2}$, and $\varepsilon_{l s 3}$ are the principal linear strain. The volumetric swelling can be determined by adding the linear strain,

$$
\varepsilon_{v s}=2 \varepsilon_{\text {lpar }}+\varepsilon_{\text {per }},
$$

where $\varepsilon_{l p a r}$ and $\varepsilon_{\text {lper }}$ are strains parallel and perpendicular to the bedding plane, respectively. To formulate Equation (9), it was assumed that the strain perpendicular and parallel to the bedding plane could be predicted using Equation (10),

$$
\varepsilon_{\text {par }}=\frac{\varepsilon_{\text {par } 1}+\varepsilon_{\text {par } 2}}{2} .
$$

\subsection{Dependence of $\mathrm{CO}_{2}$ Swelling on Coal Properties}

Because the samples used in these experiments have similar coal rank, the difference between swelling results was too small to allow meaningful comparison. Meanwhile, some authors $[5,7,11,19]$ concluded that swelling decreased with increasing coal rank. Figure 7 shows the maximum coal swelling $\left(\varepsilon_{\max }\right)$ as a function of coal rank from our results and those reported [6,7,11-13,21,22]. There is a dependence between coal rank and swelling; higher swelling corresponds to lower coal rank.

Some considerations have to be made for the LRC where the data are scattered. Coal swelling by $\mathrm{CO}_{2}$ injection is strongly controlled by $\mathrm{CO}_{2}$ adsorption volume. Based on [23], the dependence of $\mathrm{CO}_{2}$ sorption on coal properties is controlled not only by individual factors but also the combination by several factors; e.g., coal composition, TOC, ash content, dull and bright coal as well as coal rank. Meanwhile, gas sorption tends to increase with increasing rank, although some exceptions were found in [18]. Beulah-Zap lignite, which was the lowest rank of all samples, showed the highest sorption capacity.

Coal of higher rank has been subjected to a more severe stress history than LRC, so it in general exhibits more structural deformation and is thereby more difficult to swell. Larsen et al. [19] explained that higher rank coal rearranges in the opposite direction to LRC to form a less-associated structure. Thus, coal properties should be well characterized to evaluate coal swelling because swelling does not only rely on rank.

Within the sample set studied, a general tendency was observed for $D$ to increase for wet samples, although sample SK-01 was an exception. Increasing $D$ is related to the enthalpy of adsorption based on Wood's equation (Equation (11)), whereas $E$ of $\mathrm{CO}_{2}$ is reduced in the presence of moisture [7,24]. This apparent reduction in enthalpy may be caused by higher energy adsorption sites being occupied by water molecules in the wet samples (by hydrogen bonding), thus restricting gas sorption to sites of lower energy [7].

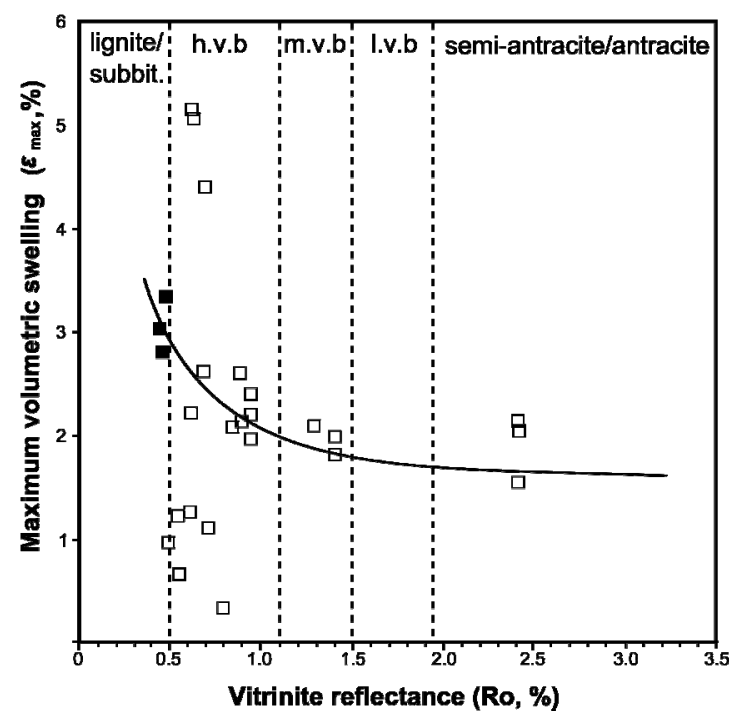

Figure 7. The maximum coal volumetric swelling $\left(\varepsilon_{\max }\right)$ as a function of coal rank (black cube represent swelling data from present experiment results). 


$$
D=\left[\frac{R T}{\beta E}\right]^{2}
$$

where $R$ is the universal gas content, $T$ is the temperature and $\beta$ is a scaling factor to account for the different affinities of sorbates for the sorbent material.

In the case of published data [7,24], high rank coal with vitrinite reflectance $\left(R_{0}\right)$ more than 0.76 [24] and 0.62 to 1.40 for [7] was used. However, the lowest rank sample in [7] showed decreasing $D$ value, which they attributed to moisture preferentially occupying polar sites on the coal surface. In dry samples, it appears that $\mathrm{CO}_{2}$ and $\mathrm{CH}_{4}$ can readily adsorb on these polar sites, but when water is present, they become unavailable to other sorbates. Thus, in moist LRCs with a high proportion of polar sites, much of the internal surface of the coal is already covered by water molecules. As a result, there is relatively little surface available for gas adsorption and therefore little swelling.

Based on our data using LRC, both decreasing and increasing $D$ values were observed. Figure 8 shows $D$ value as a function of coal rank based on current experiments and reported data $[6,7,11-13,21,22]$, which indicates that $D$ value does not have a strong dependence on coal rank. Thus, because $\mathrm{CO}_{2}$ swelling induced by $\mathrm{CO}_{2}$ adsorption correlates strongly with the amount of $\mathrm{CO}_{2}$ adsorbed, care should be taken when considering the factor(s) causing coal swelling.

\section{Conclusions}

In this study, a visualization method was used to measure

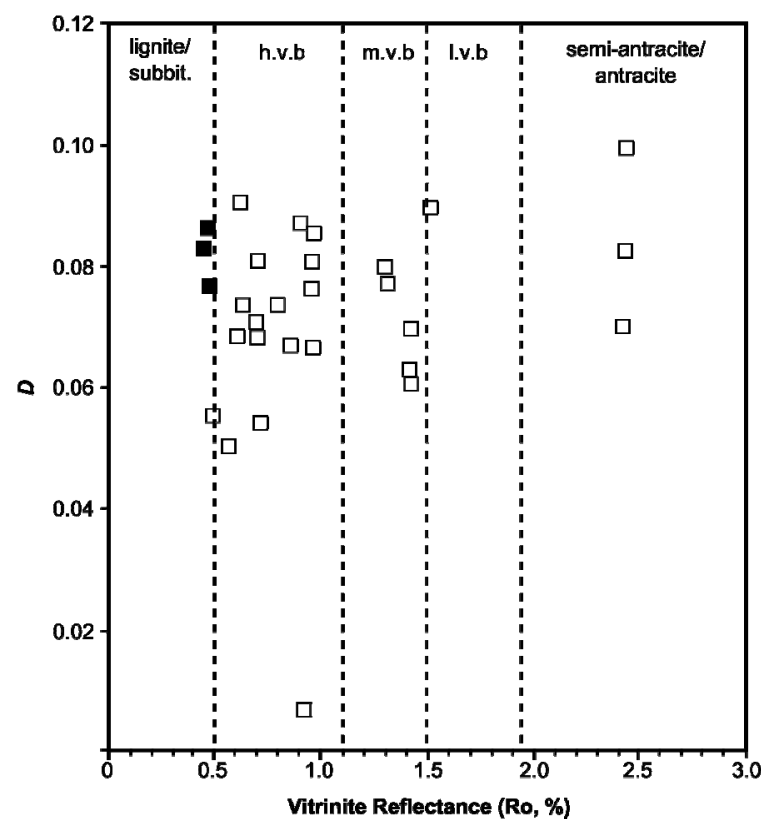

Figure 8. $D$ value as a function of coal rank (black cube represent swelling data from present experiment results). swelling of crushed coal samples in a pressure cell with $\mathrm{CO}_{2}$ pressure of 0.1 to $10 \mathrm{MPa}$ and temperature of $48^{\circ} \mathrm{C}$. Crushed coal samples provide benefits in terms of sample preparation and experimental ease compared with block coal samples. The other benefit of this method is the relatively short equilibrium time needed to reach maximum swelling.

Coal swelling was represented by upward surface movement of columns filled with crushed coal particles. The total expanded volume of coal particles was modeled like the swelling volume of coal block. Present swelling results were comparable with published data.

The maximum swelling volume ratios for the three coal samples achieved by $\mathrm{CO}_{2}$ adsorption were around $3 \%$ at $10 \mathrm{MPa}$ of $\mathrm{CO}_{2}$. Wet coal samples showed lower volumetric expansion than dry ones because moisture considerably reduced the degree of gas-induced swelling. Although wet coal swells less than dry samples, wet samples are in fact already partially swelled because of the presence of water. In addition to calculating swelling perpendicular and parallel to the bedding plane instead of volumetric swelling, the equation developed in this study can be used.

\section{Acknowledgements}

This study was financially supported by the JSPS KAKENHI Grant-in-Aid for Scientific Research (B); Number 24360372 .

\section{REFERENCES}

[1] D. Law, L. G. H. van der Meer and W. D. Gunter, "Numerical Simulator Comparison Study for Enhanced Coalbed Methane Recovery Processes, Part I: Pure Carbon Dioxide Injection," Proceeding of SPE Gas Technology Symposium, Calgary, 30 April-2 May 2002.

[2] C. M. White, D. H. Smith, K. L. Jones, A. L. Goodman, S. A. Jikich, R. B. LaCount, S. B. DuBose, E. Ozdemir, B. I. Morsi and K. T. Schroeder, "Sequestration of Carbon Dioxide in Coal with Enhanced Coalbed Methane Recovery A Review," Energy Fuels, Vol. 19, No. 3, 2005, pp. 659-724. doi:10.1021/ef040047w

[3] M. Fujioka, S. Yamaguchi and M. Nako, " $\mathrm{CO}_{2}-\mathrm{ECBM}$ Field Tests in the Ishikari Coal Basin of Japan," International Journal of Coal Geology, Vol. 82, No. 3-4, 2010 , pp. 287-298. doi:10.1016/j.coal.2010.01.004

[4] F. Anggara, K. Sasaki, H. Amijaya, Y. Sugai and L. D. Setjadji, " $\mathrm{CO}_{2}$ Injection in Coal Seams, an Option for Geological $\mathrm{CO}_{2}$ Storage and Enhanced Coal Bed Methane Recovery (ECBM)," Proceedings of the Indonesian Petroleum Association, 34th Annual Convention \& Exhibition, Jakarta Indonesia, 18-20 May 2010, p. 16.

[5] P. J. Reucroft and A. R. Sethuraman, "Effect of Pressure on Carbon Dioxide Induced Coal Swelling," Energy Fuels, Vol. 1, No. 1, 1987, pp. 72-75. doi:10.1021/ef00001a013 
[6] S. Day, R. Fry and R. Sakurovs, "Swelling of Australian Coals in Supercritical $\mathrm{CO}_{2}$," International Journal of Coal Geology, Vol. 74, No. 1, 2008, pp. 41-52. doi:10.1016/j.coal.2007.09.006

[7] S. Day, R. Fry and R. Sakurovs, "Swelling of Moist Coal in Carbon Dioxide and Methane," International Journal of Coal Geology, Vol. 86, No. 2-3, 2011, pp. 197-203. doi:10.1016/j.coal.2011.01.008

[8] F. V. Bergen, H. Pagnier and P. Krzystolik, "Field Experiment of Enhanced Coalbed Methane- $\mathrm{CO}_{2}$ in the Upper Silesian Basin of Poland," Environmental Geosciences, Vol. 13, No. 3, 2006, pp. 201-224. doi:10.1306/eg.02130605018

[9] K. Sasaki, F. Anggara and Y. Sugai, "Coal-Matrix Swelling by $\mathrm{CO}_{2}$ Adsorption and a Model of Permeability Reduction," Proceedings of the 22nd World Mining Congress and Exp., Intanbul, 11-16 September 2011, pp. 349353.

[10] S. Bachu, " $\mathrm{CO}_{2}$ Storage in Geological Media: Role, Means, Status and Barriers to Deployment," Progress in Energy and Combustion Science, Vol. 34, No. 2, 2008, pp. 254273. doi:10.1016/i.pecs.2007.10.001

[11] J. R. Levine, "Model Study of the Influence of Matrix Shrinkage on Absolute Permeability of Coal Bed Reservoirs," Geological Society, London, Special Publications, Vol. 109, No. 1, 1996, pp. 197-212. doi:10.1144/GSL.SP.1996.109.01.14

[12] S. Durucan, M. Ahsanb and J.-Q. Shia, "Matrix Shrinkage and Swelling Characteristics of European Coals," Energy Procedia, Vol. 1, No. 1, 2009, pp. 3055-3062. doi:10.1016/j.egypro.2009.02.084

[13] E. Battistutta, P. van Hemert, M. Lutynski, H. Bruining and K.-H. Wolf, "Swelling and Sorption Experiments on Methane, Nitrogen and Carbon Dioxide on Dry Selar Cornish Coal," International Journal of Coal Geology, Vol. 84, No. 1, 2010, pp. 39-48. doi:10.1016/j.coal.2010.08.002

[14] A. Busch, Y. Gensterblum, B. M. Krooss and R. Littke, "Methane and Carbon Dioxide Adsorption-Diffusion Experiments on Coal: Upscaling and Modeling," International Journal of Coal Geology, Vol. 60, No. 2-4, 2004, pp. 151-168. doi:10.1016/j.coal.2004.05.002

[15] I. Gray, "Reservoir Engineering in Coal Seams: Part 1The Physical Process of Gas Storage and Movement in
Coal Seams," SPE Reservoir Engineering, Vol. 2, No. 1, 1987, pp. 28-34.

[16] J. Seidle and L. Huitt, "Experimental Measurement of Coal Matrix Shrinkage Due to Gas Desorption and Implications for Cleat Permeability Increases," Proceeding of International Meeting on Petroleum Engineering, Beijing, 14-17 November 1995, pp. 575-582.

[17] Y. Otake and E. M. Suuberg, "Temperature Dependence of Solvent Swelling and Diffusion Processes in Coals," Energy Fuels, Vol. 11, No. 6, 1997, pp. 1155-1164. doi:10.1021/ef970020v

[18] A. Busch, Y. Gensterblum and B. M. Krooss, "Methane and $\mathrm{CO}_{2}$ Sorption and Desorption Measurements on Dry Argonne Premium Coals: Pure Components and Mixtures," International Journal of Coal Geology, Vol. 55, No. 2-4, 2003, pp. 205-224. doi:10.1016/S0166-5162(03)00113-7

[19] J. W. Larsen, R. A. Flowers, P. J. Hall and G. Carlson, "Structural Rearrangement of Strained Coals," Energy Fuels, Vol. 11, No. 5, 1997, pp. 998-1002. doi:10.1016/i.fuel.2010.05.038

[20] Z. Pan, L. D. Connell, M. Camilleri and L. Connelly, "Effects of Matrix Moisture on Gas Diffusion and Flow in Coal," Fuel, Vol. 89, No. 11, 2010, pp. 3207-3217. doi:10.1021/ef970014z

[21] F. Anggara, K. Sasaki and Y. Sugai, "Matrix Deformation Characteristics of Kushiro Coal," Proceedings of the Japanese Association for Petroleum Technology 77th Annual Meeting and Convention, Chiba, 27-28 September 2012, 5 p.

[22] S. Day, R. Fry, R. Sakurovs and S. Weir, "Swelling of Coals by Supercritical Gases and Its Relationship to Sorption," Energy \& Fuels, Vol. 24, No. 4, 2010, pp. 2777-2783. doi:10.1021/ef901588h

[23] A. Busch and Y. Gensterblum, "CBM and $\mathrm{CO}_{2}$-ECBM Related Sorption Processes in Coal: A Review," International Journal of Coal Geology, Vol. 87, No. 2, 2011, pp. 49-71. doi:10.1016/j.coal.2011.04.011

[24] D. Prinz and R. Littke, "Development of the Micro- and Ultramicroporous Structure of Coals with Rank as Deduced from the Accessibility to Water," Fuel, Vol. 84, No. 12-13, 2005, pp. 1645-1652. doi:10.1016/j.fuel.2005.01.010 